\title{
Mantle cell leukemia as a cause of leukostasis
}

This article was published in the following Dove Press journal:

Blood and Lymphatic Cancer: Targets and Therapy

22 April 2011

Number of times this article has been viewed

\section{Daniel Smith' \\ Christian Cable ${ }^{2}$ \\ Cary Chisholm' \\ Walter Linz' \\ William Koss' \\ Sheila Dobin' \\ Edward Rappaport' \\ 'Department of Pathology, ${ }^{2}$ Internal Medicine, Scott and White Healthcare/Texas A \& M Health Science Center College of Medicine, Temple, TX, USA}

Correspondence: Daniel Smith Department of Pathology, 240I South 3Ist Street, Temple, TX 76508, USA

Tel: + I 2547242435

Fax: + 254724439 |

email: dansmith@swmail.sw.org
Abstract: A 72-year-old man was admitted with hypoxemic respiratory distress. Given a white blood cell count of $600 \times 10^{9} / \mathrm{L}$ and symptoms of leukostasis, emergency leukapheresis was initiated. The white blood cell count immediately after the first leukapheresis was paradoxically increased to over $700 \times 10^{9} / \mathrm{L}$. Peripheral blood smear findings showed morphologically immature mononuclear cells and numerous circulating mitotic figures. Initial flow cytometry results showed a lambda light chain-restricted B lymphoid population positive for CD20, CD19, CD5, and FMC-7, and negative for TdT, CD10, CD23, CD34, CD117, and myeloid markers, suggesting classification as a blastoid variant of mantle cell lymphoma in a leukemic phase. Subsequent testing using DNA fluorescence in situ hybridization was positive for $\mathrm{t}(11 ; 14)$, confirming the diagnosis of mantle cell leukemia. Although mantle cell lymphoma occasionally transforms or can even present as leukemia (leukocytes $>40 \times 109 / \mathrm{L}$ ), it is rare for it to present with such profound leukocytosis and an overwhelming number of pleomorphic/blastoid forms. Although morphology suggested acute lymphoblastic leukemia, a more specific diagnosis of blastoid variant mantle cell lymphoma was obtained in 12 hours by applying complementary techniques of flow cytometry and rapid cytogenetics.

Keywords: mantle cell lymphoma, chemotherapy, leukapheresis, lymphocytic leukemia

\section{Introduction}

Mantle cell lymphoma is a B cell neoplasm that represents an estimated 3\%-10\% of all non-Hodgkin's lymphomas. ${ }^{1}$ Mantle cell lymphoma often mimics chronic lymphocytic leukemia and is difficult to treat. Mantle cell lymphoma is most often characterized by a homogenous population of small- to medium-sized lymphocytes with scant cytoplasm, irregular nuclear contours, and is almost always associated with the chromosomal translocation $\mathrm{t}(11 ; 14)(\mathrm{q} 13 ; \mathrm{q} 32)$, resulting in the rearrangement of bcl-1 and overexpression of cyclin D1.2-4 Mantle cell lymphoma cells usually express surface IgM and IgD, and are positive for CD5, CD19, CD20, CD43, and FMC-7., 1,5 They are usually negative for CD10, bc16, and CD23. Additionally, all are positive for bcl2 and most for cyclin D1. The rare cases of mantle cell lymphoma which are negative for cyclin D1 express either cyclin D2 or cyclin D3, and show a better prognosis than the typical cyclin D1 positive mantle cell lymphoma. ${ }^{1}$

The World Health Organization currently recognizes four morphologic variants of mantle cell lymphoma. Two variants do not appear to carry prognostic value, but may be challenging to diagnose morphologically. Those variants are the small cell variant which mimics chronic lymphocytic leukemia/small cell lymphoma and the marginal zone-like variant which mimics marginal zone lymphoma. The other two are 
"aggressive" variants and carry a worse clinical prognosis. These are the blastoid and pleomorphic variants. Aggressive variants have been shown to carry more cytogenetic abnormalities than the less aggressive variants, most notably c-myc gene abnormalities, p53 gene abnormalities, and p16 ${ }^{\mathrm{INK} 4 \mathrm{a}}$ deletions..$^{6-8}$ In addition to mutations and deletions, cell cycle inhibitors are often transcriptionally repressed in these variants. ${ }^{9}$

At least $77 \%$ of patients with mantle cell lymphoma present with peripheral blood involvement by flow cytometry; however, most cases do not have an absolute lymphocytosis at the time of diagnosis. ${ }^{1,10}$ The leukemic phase of mantle cell lymphoma is defined as an absolute tumor white cell count of greater than $40 \times 10^{9} / \mathrm{L}^{1}$. Very few cases have been reported with peripheral counts exceeding $300 \times 10^{9} / \mathrm{L}^{11,12}$ We report a case of mantle cell lymphoma presenting with a hyperleukocytosis over $650 \times 10^{9} / \mathrm{L}$, with pulmonary leukostasis. This case also illustrates the importance of consistently performing immunophenotype and molecular studies, because the diagnosis of mantle cell lymphoma may be overlooked if the appropriate information is not obtained.

\section{Case report}

A 72-year-old man was transferred to our intensive care unit in critical condition at midnight, with a clinical diagnosis of acute leukemia. He was admitted with hypoxemic respiratory distress secondary to pulmonary leukostasis. The hypoxemia was measured by pulse oximetry (noninvasive) and showed $91 \%$ saturation on $30 \% \mathrm{FiO}_{2}$ by venturi mask. He had a white blood cell count of $682 \times 10^{9} / \mathrm{L}$, a hemoglobin of $8 \mathrm{gm} / \mathrm{dL}$, and a platelet count of $59,000 \times 10^{9} / \mathrm{L}$. The white blood cell morphology suggested acute lymphoblastic leukemia with few prolymphocytes (Figure 1). Emergency leukapheresis was initiated during the night of admission. A repeat complete blood count immediately after apheresis showed the white blood cell count to be $766 \times 10^{9} / \mathrm{L}$.

Flow cytometry performed at 8 am showed a lambda light chain-restricted B lymphoid population that was positive for CD19, CD20, CD5, and FMC-7. The same population was negative for TdT, CD10, CD23, CD34, CD117, and myeloid markers, CD13 and CD33. Lambda restriction and CD20 expression, along with the notable absence of CD23, was consistent with the blastoid variant of mantle cell lymphoma in a leukemic phase. At noon the same day, testing with DNA fluorescence in situ hybridization was positive for $\mathrm{t}(11 ; 14)$, confirming the diagnosis of mantle cell leukemia (Figure 2). Subsequent cytogenetic studies

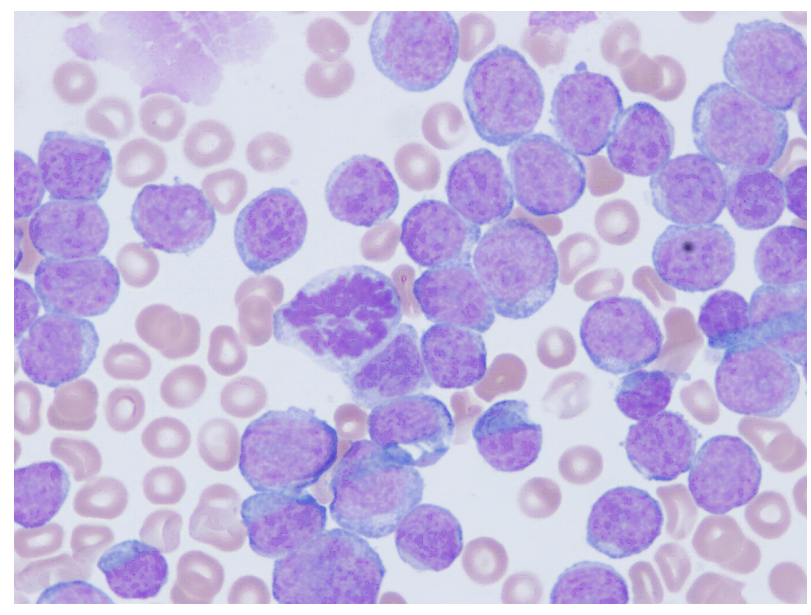

Figure I Peripheral blood smear demonstrating a spectrum of immature mononuclear cells with mitotic cells readily identified. Blasts have high nuclear/cytoplasmic ratios and nuclei containing prominent nucleoli and open delicate chromatin (1000× magnification).

demonstrated additional translocations at $\mathrm{t}(4 ; 8)(\mathrm{q} 21 ; \mathrm{q} 24)$ and $\mathrm{t}(8 ; 10)(\mathrm{q} 13 ; \mathrm{p} 13)$, as shown in Figure 3. A bone marrow biopsy was not indicated.

Chemotherapy was initiated 12 hours after the patient's admission. Although mantle cell lymphoma occasionally transforms or can even present as leukemia (leukocytes $>40 \times 10^{9} / \mathrm{L}$ ), it is exceedingly rare for it to present with such profound leukocytosis and an overwhelming number of pleomorphic/blastoid forms. The high proliferative rate of this tumor was demonstrated by the unusually high white blood cell count which was not responsive to leukapheresis. Morphology suggested acute lymphoblastic leukemia. The more specific diagnosis of blastoid variant mantle cell lymphoma was obtained 12 hours after the initial blood smear review following ancillary studies, including

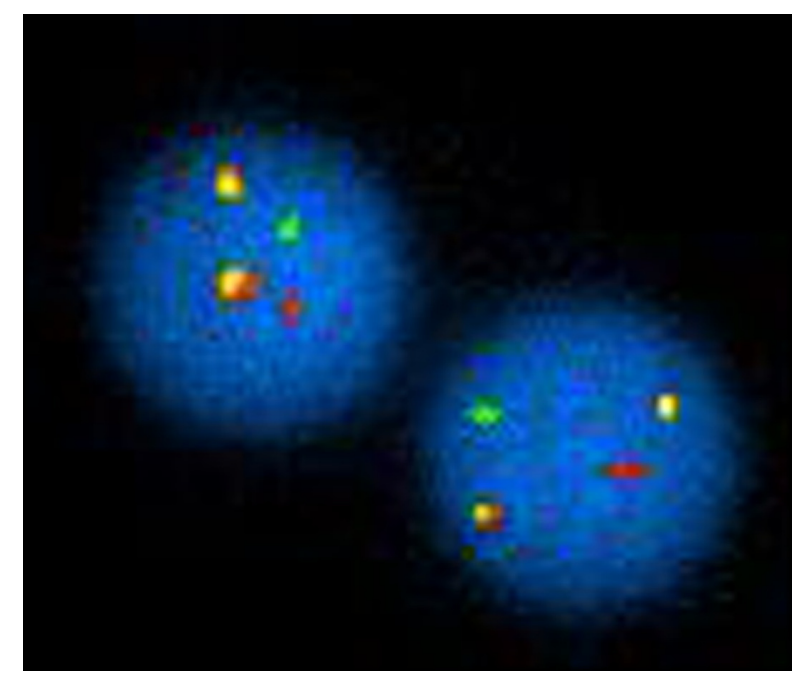

Figure 2 DNA fluorescence in situ hybridization positive for $t(I I ; \mid 4)$. 


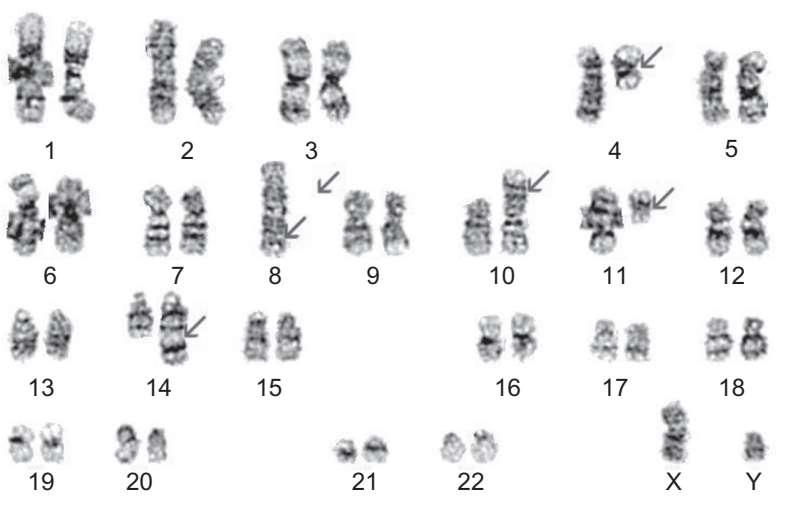

Figure 3 Karyotype: 45,XY,t(4;8)(q2।;q24),-8, $\operatorname{der}(10) \mathrm{t}(8 ; 10)(\mathrm{q}|3 ; \mathrm{p}| 3), \mathrm{t}(\mathrm{I}|\mathrm{i}| 4)$ $(q \mid 3 ; q 32)[7]$.

flow cytometry and rapid and specific targeting of molecular markers by fluorescence in situ hybridization.

\section{Discussion}

Mantle cell lymphoma continues to be one of the more aggressive non-Hodgkin's lymphomas, usually requiring treatment upon diagnosis. Options for therapy include aggressive polychemotherapy regimens, such as hyperCVAD (cyclophosphamide, vincristine, adriamycin and dexamethasone) and rituximab, or high-dose chemotherapy with autologous hematopoietic stem cell rescue..$^{13}$ The potential for pleomorphic/blastoid mantle cell variants to behave even more aggressively has been well documented.,11,14 Several molecular abnormalities have been identified in these variants, and have been associated with their aggressive nature. The most common abnormality is a c-myc gene rearrangement in the 8q24 region which shows an accelerated course. ${ }^{7}$ Other features of poor prognosis for mantle cell lymphoma include p53 mutation, ATM deletion, $8 \mathrm{q}$ deletions, and complex cytogenetics. ${ }^{4}{ }^{15}$ In this case, only the $8 \mathrm{q} 24$ rearrangement was documented (the others were negative and p53 was not tested). In addition, we confirmed the presence of $\mathrm{t}(11 ; 14)$ and $\mathrm{t}(8 ; 10)(\mathrm{q} 13 ; \mathrm{p} 13)$ translocations which have also been well documented in the pathogenesis of mantle cell lymphoma., ${ }^{4,16}$

This patient has some similarities to the case reported by Smith et al. ${ }^{12}$ Our patient had leukostasis syndrome, albeit with different manifestations. Whereas the previous report described oculodynia and blurred vision, our patient presented with acute respiratory distress. Serial chest $\mathrm{x}$-rays showed worsening pulmonary vascular congestion and interstitial edema with bibasilar reticularnodular opacities. Interestingly, the previous case also exhibited bibasilar interstitial changes, although they were asymptomatic. Similarly, our patient received hyper-CVAD chemotherapy. Rituximab was omitted on the first cycle due to extreme lymphocytosis and concern for fatal infusion reaction. This is a black box warning concerning use of rituximab in chronic lymphocytic leukemia with high presenting lymphocyte counts. Rituximab was added to subsequent chemotherapy cycles.

Unlike the previous report, our patient started with a lower burden of leukocytosis $\left(682.1 \times 10^{9} / \mathrm{L}\right.$ with $96 \%$ blasts); however, he received only one leukapheresis procedure which was followed by a paradoxically increased leukocyte quantitation $\left(765.7 \times 10^{9} / \mathrm{L}\right.$ with $96 \%$ blasts $)$. This leukapheresis was followed with symptomatic improvement despite the worsening laboratory value. In both cases, leukapheresis improved the acute clinical picture. Leukapheresis is only an emergency procedure to treat symptoms of leukostasis and reduce tumor cell burden. The long-term impact of leukapheresis on survival is uncertain. Our patient is alive 16 months post-diagnosis. The previously reported patient died after six months, despite multiple chemotherapy treatments and numerous exchanges. Whether leukapheresis improves survival in these patients cannot be assessed given the small number of patients.

In summary, we present a case of blastoid variant mantle cell lymphoma, that highlights an unusual presentation and the importance of ancillary studies to confirm the diagnosis appropriately. The aggressive nature of this variant, including a rapid clinical onset, hyperleukocytosis over $600 \times 10^{9} / \mathrm{L}$, and pulmonary leukostasis, also illustrate the medical emergency of this specific presentation. Perhaps most importantly, this case demonstrates the importance of having good interdepartmental communication, with a team approach to overcome a potentially fatal medical emergency, while also establishing the unexpected diagnosis of mantle cell lymphoma so that this patient could be rapidly and appropriately treated.

\section{Disclosure}

The authors report no conflicts of interest in this work.

\section{References}

1. Swerdlow SH, Seto M, Muller-Hermelink HK. Mantle Cell Lymphoma Lyon, France: International Agency for Research on Cancer Press; 2008 .

2. Medeiros LJ, Van Krieken JH, Jaffe ES, Raffeld M. Association of bcl-1 rearrangements with lymphocytic lymphoma of intermediate differentiation. Blood. 1990;76:2086-2090.

3. Viswanatha DS, Foucar K, Berry BR, Gascoyne RD, Evans HL, Leith CP. Blastic mantle cell leukemia: An unusual presentation of blastic mantle cell lymphoma. Mod Pathol. 2000;13:825-833. 
4. Zamo A, Katzenberger T, Adam P, et al. Establishment of the MAVER-1 cell line, a model for leukemic and aggressive mantle cell lymphoma. Haematologica. 2006;91:40-47.

5. Gao J, Peterson L, Nelson B, Goolsby C, Chen YH. Immunophenotypic variations in mantle cell lymphoma. Am J Clin Pathol. 2009;132: 699-706.

6. Greiner TC, Moynihan MJ, Chan WC, et al. p53 mutations in mantle cell lymphoma are associated with variant cytology and predict a poor prognosis. Blood. 1996;87:4302-4310.

7. Hao S, Sanger W, Onciu M, Lai R, Schlette EJ, Medeiros LJ. Mantle cell lymphoma with 8q24 chromosomal abnormalities: A report of 5 cases with blastoid features. Mod Pathol. 2002;15:1266-1272.

8. Hutter G, Scheubner M, Zimmermann Y, et al. Differential effect of epigenetic alterations and genomic deletions of CDK inhibitors [p16(INK4a), p15(INK4b), p14(ARF)] in mantle cell lymphoma. Genes Chromosomes Cancer. 2006;45:203-210.

9. Sanchez-Beato M, Sanchez-Aguilera A, Piris MA. Cell cycle deregulation in B-cell lymphomas. Blood. 2003;101:1220-1235.

10. Cohen PL. Bone marrow and peripheral blood involvement in mantle cell lymphoma. Br J Haematol. 1998;101:302-310.
11. Schlette E, Lai R, Oncui M, Doherty D, Bueso-Ramos C, Medeiros LJ. Leukemic mantle cell lymphoma: Clinical and pathologic spectrum of twenty-three cases. Mod Pathol. 2001;14:1133-1140.

12. Smith MD, Singleton TP, Balaraman S, et al. Case report: Mantle cell lymphoma, prolymphocytoid variant, with leukostasis syndrome. Mod Pathol. 2004;17:879-883.

13. Bernard M, Gressin R, Lefrere F, et al. Blastic variant of mantle cell lymphoma: A rare but highly aggressive subtype. Leukemia. 2001;15: 1785-1791.

14. Pittaluga S, Verhoef G, Criel A, et al. Prognostic significance of bone marrow trephine and peripheral blood smears in 55 patients with mantle cell lymphoma. Leuk Lymphoma. 1996;21:115-125.

15. Greiner TC, Dasgupta C, Ho W, et al. Mutation and genomic deletion status of ataxia telangiectasia mutated (ATM) and p53 confer specific gene expression profiles in mantle cell lymphoma. Proc Natl Acad Sci US A. 2006;103:2352-2357.

16. Kohlhammer H, Schwaenen C, Wessondorf S, et al. Genomic DNA-chip hybridization in $\mathrm{t}(11 ; 14)$-positive mantle cell lymphomas shows a high frequency of aberrations and allows a refined characterization of consensus regions. Blood. 2004;104:795-801.

\section{Dovepress}

\section{Publish your work in this journal}

Blood and Lymphatic Cancer: Targets and Therapy is an international, peer-reviewed, open access journal focusing on blood and lymphatic cancer research, identification of therapeutic targets and the optimal use of preventative and integrated treatment interventions to achieve improved outcomes, enhanced survival and quality of life for the cancer patient. The manuscript management system is completely online and includes a very quick and fair peer-review system. Visit http://www.dovepress.com/testimonials.php to read real quotes from published authors. 